\title{
Data centres in future European energy systems - energy efficiency, integration and policy
}

\author{
Carolina Koronen • Max Åhman (1) • Lars J Nilsson
}

Received: 15 February 2019/Accepted: 27 November 2019/Published online: 12 December 2019

(C) The Author(s) 2019

\begin{abstract}
End-use efficiency, demand response and coupling of different energy vectors are important aspects of future renewable energy systems. Growth in the number of data centres is leading to an increase in electricity demand and the emergence of a new electricity-intensive industry. Studies on data centres and energy use have so far focused mainly on energy efficiency. This paper contributes with an assessment of the potential for energy system integration of data centres via demand response and waste heat utilization, and with a review of EU policies relevant to this. Waste heat utilization is mainly an option for data centres that are close to district heating systems. Flexible electricity demand can be achieved through temporal and spatial scheduling of data centre operations. This could provide more than $10 \mathrm{GW}$ of demand response in the European electricity system in 2030. Most data centres also have auxiliary power systems employing batteries and stand-by diesel generators, which could potentially be used in power system balancing. These potentials have received little attention so far and have not yet been
\end{abstract}

\section{Koronen}

Department of Electrical Engineering and Power Electronics, Vrije Universiteit Brussel, Pleinlaan 2, 1050 Brussels, Belgium

e-mail: Carolina.koronen@vub.be

\section{M. Åhman $(\bowtie) \cdot$ L. J. Nilsson}

Department of Environmental and Energy Systems Studies, Lund University, PO Box 118, SE-221 00 Lund, Sweden

e-mail: Max.ahman@miljo.lth.se

L. J. Nilsson

e-mail: Lars.nilsson@miljo.lth.se considered in policies concerning energy or data centres. Policies are needed to capture the potential societal benefits of energy system integration of data centres. In the EU, such policies are in their nascent phase and mainly focused on energy efficiency through the voluntary Code of Conduct and criteria under the EU Ecodesign Directive. Some research and development in the field of energy efficiency and integration is also supported through the EU Horizon 2020 programme. Our analysis shows that there is considerable potential for demand response and energy system integration. This motivates greater efforts in developing future policies, policy coordination, and changes in regulation, taxation and electricity market design.

Keywords Data centres · EU policy - Digitalization . Demand response $\cdot$ Sector coupling $\cdot$ Energy efficiency

\section{Introduction}

Data centres are becoming an increasingly critical part of the infrastructure for the digitalized society. Digitalization, high-speed wireless networks, new dataintensive technologies and a rising demand for cloud computing have led to the development of data centres ${ }^{1}$ from a few enterprise computing centrals to major electricity-intensive industry. The share of global electricity used by data centres is currently estimated to be

\footnotetext{
${ }^{1}$ A data centre is a facility dedicated to the operation of equipment providing data processing and storage. It typically consists of servers, storage devices and communication networks, together with ancillary equipment required for cooling and power supply.
} 
about $1 \%$ (IEA 2017), but the steady increase in data processing, storage and traffic is cause for concern regarding the future electricity demand of this industry (Andrae and Edler 2015,Andrae 2018).

The potential growth in the number of large-scale data centres and their associated electricity demand should be seen in the light of rapidly changing power systems with increasingly larger shares of variable renewable energy. An electricity sector relying mainly on renewables is the cornerstone in achieving a climate neutral EU by 2050 (European Commission 2019). The total electricity consumption in the EU has increased only slightly since 2000 , mainly in the service and housing sectors (Eurostat 2019). Driven by the recent dramatic fall in the price of solar photovoltaic cells and wind power (IRENA 2019), several long-term scenarios project that the demand for electricity could increase substantially as both the transport and the industrial sectors become electrified (Lechtenböhmer et al. 2016). These traditional sectors have been analysed carefully from an energy system perspective. However, data centres constitute a new sector, and has not yet been included in energy economic modelling or studied as a separate part of EU long-term climate strategies (see, e.g. European Commission 2011, European Commission 2018).

There is a growing body of literature dealing with the electricity demand and energy efficiency of data centres, as well as studies on renewable energy integration, as a means of reducing the environmental impact of power generation and reducing electricity costs for data centre operators. Several extensive studies (Masanet et al. 2011; Shehabi et al. 2016) have been carried out to estimate the total electricity consumption of the full spectrum of US data centres. Key strategies and technologies for increased energy efficiency in data centres have been reviewed by several groups, for example, Oró et al. (2015), Rong et al. (2016) and Ni and Bai (2016). Rahman et al. (2014) reviewed power management techniques for data centres, including strategies for increased integration of renewable energy sources. Integration opportunities via waste heat use or demand response have been explored by Shuja et al. (2016) and Ghatikar et al. (2012), respectively. However, few studies have been carried out on data centre development using a broader energy system perspective, to explore the potential system benefits of data centre and renewable energy system integration. By using the potential for demand response and heat integration, the data centre industry could facilitate the transition to renewable electricity, rather than simply being a power load.

The aim of this study was to assess the potential for the integration of data centres in evolving energy systems with increasing shares of variable electricity, and to discuss how EU policy could be developed to reap potential benefits. Growth and technical development in the data centre industry are rapid, and thus very uncertain. As the data centre industry is still in a formative phase, this study is motivated by the fact that considerable societal benefits may be achieved by supporting not only end-use efficiency but also demand response and energy system integration of data centres. This paper is based on a literature review of the technical potential for energy efficiency, demand response and heat integration, together with mapping of EU policies relevant to the data centre industry, and an analysis of this potential in a 2030 scenario for the EU.

We begin in "Energy system and data centre development" by describing the predicted development of energy systems and data centres in the EU up to 2030. In "The technical potential for energy-efficient and integrated data centres", we review and analyse the potential for improved efficiency, demand response and heat integration, and in "Current EU policies concerning data centres and energy", we map the EU policies affecting data centres. Based on the potential identified and on the predicted development, we assess the potential for energy system integration and improved efficiency within the EU in 2030, and analyse the policy challenges. Based on this analysis, we identify weaknesses and suggest strategies for improvement in "Concluding discussion".

\section{Energy system and data centre development}

Decarbonizing the electricity sector in the EU

The transition to renewable energy sources is changing how power systems function by increasing the need for demand response and energy storage to maintain grid balance and power quality (Haas et al. 2013, SchleisserTappesser 2012). Future EU electricity production is expected to be dominated by variable renewable energy sources. If the EU's climate and energy goals for 2030 are met (reducing GHG emissions by $40 \%$ compared to 
1990 levels; having 27\% renewable energy sources in the energy mix; and reaching $27 \%$ energy efficiency compared to projected levels), the European Commission's Joint Research Centre (EC-JRC) predicts that the share of renewables in the gross generated electricity mix in the EU in 2030 will reach 47\% (Banja and Jégard 2017). The total installed capacity for power generation in the EU in 2030 is projected to reach $652 \mathrm{GW}$ (compared to $406 \mathrm{GW}$ in 2016), where non-dispatchable wind and solar power are projected to account for over $500 \mathrm{GW}$. This figure is conservative. The share of nondispatchable electricity in the EU electricity system may exceed $50 \%$ by 2030 (Banja and Jégard 2017), or even $60 \%$ (Artelys 2017), due to low-cost renewable electricity technologies simply outcompeting coal and gas. The ambition and trajectory of future EU policy and renewable electricity development indicate a power market dominated by non-dispatchable renewable electricity by 2040-2050 (European Commission 2011, Artelys 2017).

It is expected that up to 40-50\% renewable electricity could be integrated into the current power system, within the current market regime, by activating existing flexibility options (e.g. demand response, storage and flexible power production) in the system (Papaefthymiou and Dragoon 2016). However, at levels of non-dispatchable renewables above $70-80 \%$, the need for flexibility increases rapidly, especially on longer timescales (weekly and seasonal storage) (ibid). This will create a rapidly growing market for both demand response and for storage options on varying timescales. For example, Kondziella and Bruckner (2016) estimate that in a $100 \%$ renewable electricity system, up to $40 \%$ of the total electricity demand must be supplied via flexibility measures such as batteries or demand response in order to maintain the grid balance.

\section{Electricity demand of data centres in 2030}

The earliest estimates of the electricity demand of data centres indicated that they used about $150 \mathrm{TWh}$, corresponding to $1 \%$ of the total global electricity use, in 2005 (Koomey 2008), and roughly $200 \mathrm{TWh}$, or 1.1 to $1.5 \%$ of the global electricity use, in 2010 (Koomey 2011). A similar figure has been presented by Andrae and Edler (2015), who estimated the data centre share of global electricity use in 2010 to be $1 \%$. The IEA describes the number of recent comprehensive studies on data centre global electricity demand as "limited", and inconsistencies in the methods and system boundaries used make comparisons difficult. Nonetheless, the IEA estimates that in 2014, data centres worldwide consumed 194 TWh electricity, corresponding to $1 \%$ of the global electricity demand (IEA 2017).

Koomey's (2008) estimate of the total electricity use of data centres in Western Europe in 2005 was 41.4 TWh. In a report by Bertoldi et al. (2012), published by the EC-JRC, the total data centre electricity consumption in the EU-27 in 2007 was estimated to be 56 TWh. The European Commission (2015) estimated that the electricity used by data centres in the EU-28 in 2015 was $78 \mathrm{TWh}$, which is equivalent to $2.5 \%$ of the total EU electricity use. However, the methodologies used and the scope of these studies vary, and they do not accurately portray growth over time.

The demand for data centre services is growing rapidly, as reflected in the global amount of data centre traffic and the number of workloads ${ }^{2}$ and computing instances, all of which are expected to increase in the coming years. Global IP traffic is expected to increase at a compound annual growth rate of $25 \%$ during the period 2016-2021. The corresponding value for workloads and computing instances is $19 \%$, which is equivalent to a doubling every 4 years (Cisco 2018).

The information and communications technology (ICT) sector is developing towards increased centralization as cloud computing and data centres take over work from consumer devices such as laptops, tablets and smartphones (Andrae and Edler 2015). As many businesses are discovering the advantages of cloud computing, a shift is taking place from traditional small-scale server installations, or "closet servers", often with poor energy performance, to more efficient, large-scale cloud data centres. It is expected that by 2021 the majority of servers, as well as processing power, data traffic and stored data, will be collected in a few mega-scale ${ }^{3}$ cloud data centres owned by one of a handful of internet companies (Cisco 2018).

The electricity demand for data handling is generally expected to grow, but it is uncertain by how much. After a period of high growth rates in the

\footnotetext{
$\overline{{ }^{2} \text { Cisco (2016) }}$ defines a workload as "a virtual or physical set of computer resources, including storage, that are assigned to run a specific application or provide computing services for one to many users; [it] is a general measurement used to describe many different applications".

${ }^{3}$ A data centre with an installed load of over $10 \mathrm{MW}$, sometimes several $100 \mathrm{MW}$.
} 
2000s, a slowing down has been seen since 2010 . This is mainly explained by efficiency gains through a shift from smaller servers to large-scale centralized data centres with substantially better energy performance (Van Heddeghem et al. 2014). The European Commission (2015) expects that the demand for electricity for data centres will start to increase slowly again in 2020. The IEA (2017) estimated a modest $3 \%$ increase in global data centre electricity demand over the years 2014-2020. Although blockchain technology currently only accounts about 0.1 to $0.3 \%$ of global electricity consumption, its popularization could have significant effects on data centre electricity use (IEA 2019). In a more alarmist estimate of future global data centre electricity use, Andrae and Edler (2015) suggest that the increasing demand for digital services could outpace efficiency improvements. In this scenario, the global power demand of data centres could reach as much as $13 \%$ of global electricity use in 2030, corresponding to a 14-fold increase compared with 2010 (ibid). However, in a more recent study, Andrae (2018) revised this value to $3 \%$ of global electricity use in 2025 .

\section{The technical potential for energy-efficient and integrated data centres}

As an emerging electricity-intensive industry, data centres can have considerable impact-negative or positive - on future energy systems. To be sustainable in an energy system perspective, data centres must not only be energy-efficient but must also contribute to a well-functioning renewable power system via various integration alternatives, which are discussed below.

The equipment at data centres is commonly divided into IT equipment and ancillary equipment. IT equipment includes servers, storage devices and communication networks that are directly involved in delivering the core functionalities of the data centre, i.e. the storage, processing and transmission of data. The ancillary equipment includes primarily a cooling system and power infrastructure, but also lighting, security and other minor supporting equipment. Data centres usually also have an emergency power supply system based on batteries and/or diesel generators to ensure an uninterruptible power supply (UPS) in the case of a grid power failure.
Energy efficiency potential

Data centre energy efficiency is a complex issue that goes beyond the efficiency of the equipment. The resources needed to provide a certain digital service depend on the system's performance, which is influenced not only by equipment design but also software architecture, resource allocation and operational set points. The complexity of the system and the difficulty in defining what is useful work ("one unit of digital service") is why it is practically impossible to objectively measure and compare data centre efficiency using general metrics.

Nonetheless, there are many ways through which the data centre industry can become more energy-efficient. For analytical reasons, we discuss potential improvements in energy efficiency in data centres on three different system levels: IT equipment efficiency, ancillary equipment efficiency and efficient computing management. In practice, these categories are interdependent; for example, the choice of components will affect the applicability of different management strategies.

\section{IT equipment efficiency}

IT equipment efficiency is expected to improve following historical trends. Computing electrical efficiency (the number of computations that can be performed per $\mathrm{kWh}$ ) has doubled every 1.5 years for over 65 years (Wong et al. 2011), as a result of the continuous decrease in transistor size, and is commonly referred to as Moore's law. This exponential improvement in computer capacity and energy performance is an enabler for the growth of the ICT industry, by making increased computing capacity affordable and compact. According to chip maker Intel, in 2015, this development is expected to continue for "at least ten more years" (The Economist 2015), and is one of the major sources of increased data centre efficiency that will allow the industry to manage the growing workload without an exorbitant increase in electricity demand. The European Commission and the IEA refer to this as "increased chip performance" in their explanation as to why the increase in electricity demand remains moderate in their projections. However, it has been reported that the increase in chip performance has slowed down since 2012, and continued improvements have recently been questioned as we are approaching several physical and engineering limits associated with silicon-based chips (Waldrop 2016). 
New paradigms that can overcome the physical barriers of silicon-based chips are envisaged (e.g. quantum computing or "millivolt switches"), and although research is ongoing, no solutions have yet become commercially available (European Commission 2015). It is not clear how long chip performance can continue to improve at the current rate. Andrae and Edler (2015), for example, assume a slowdown in the rate of efficiency improvement after 2022.

\section{Ancillary equipment efficiency}

The potential for improvements in ancillary equipment energy efficiency lies mainly in designing a highly efficient cooling system. The electricity demand for cooling has so far been one of the main reasons for the overall low energy efficiency of data centres, measured as power use efficiency (PUE) defined as follows: (total electricity demand) / (IT equipment electricity demand).

Using a traditional vapour compression refrigeration system typically means that 30 to $50 \%$ of the total electricity consumed in a data centre is used for cooling. Electrical losses in ancillary equipment account for roughly a further $10 \%$ of the electricity used (e.g. Rong et al. 2016). Most of the electrical losses can usually be attributed to the double conversion mechanism (converting AC to DC and back to AC) in the UPS. It is difficult to reduce these losses. If the grid supply is considered to be very stable, it may be possible to eliminate the UPS (Boden Type DC One 2018), but in most cases, this is considered too risky. Cooling technologies have therefore been the main focus of efficiency measures for ancillary equipment in this industry.

Among the most common, cooling efficiency strategies today are optimizing the air flow and using natural cooling sources. If the air flow is well designed, cold and hot air can be kept separate, which allows temperature set points in the mechanical cooling equipment to be increased $(\mathrm{Ni}$ and Bai 2016), resulting in significant savings in electricity. According to Wang et al. (2013), raising the set point by $1{ }^{\circ} \mathrm{C}$ saves between 4.3 and $9.8 \%$ of the electricity required for cooling. Further savings can be made by eliminating local hotspots and making the air flow smoother, which reduces the electricity required to run the fans that circulate the air (Rong et al. 2016). The cost of carefully designing the layout and ventilation for optimal airflow in a large data centre can amount to $10 \%$ of the total investment cost, but the payback time of this investment is only 2 to 3 years (Rong et al. 2016).
Efforts to improve cooling efficiency over the past 10 years have led to the development of cooling systems that use ambient air or water for cooling to a greater extent, so-called free cooling (Zhang et al. 2014). Free cooling can be used to replace part, or all, of the mechanical cooling equipment, thus saving electricity. Free cooling requires larger investments, but results in lower operating costs (Heslin 2014). A prerequisite for this is that the data centre is located in a region with a relatively cold climate, and/or close to a body of water that can be used as a cooling source. The choice of location for data centres thus has considerable influence on the electricity required for cooling. Rong et al. (2016) conclude that the appropriate choice of site and making rational use of free cooling can typically result in overall electricity savings of 12 to $15 \%$ in a data centre.

Air-based cooling systems for data centres dominate today, but are being replaced with liquid cooling systems. The development of liquid cooling systems is driven by increasing chip performance, as this results in servers with higher heat densities. Air has a relatively low heat capacity compared to liquids (water or organic liquids), and is expected to be inadequate for cooling new servers. Other drivers of liquid cooling systems are the reduced cost associated with energy and space savings, and the potential of exploiting the outlet temperature of the liquid coolant to increase the reuse of waste heat (Ebrahimi et al. 2014; Capozzoli and Primiceri 2015). Liquid cooling systems may have many different configurations, and several new concepts are being developed (e.g. Murshed and de Castro 2017; Khalaj and Halgamuge 2017).

Frontrunners in the data centre industry who have expanded in recent years have achieved high energy efficiency with PUE values below 1.1 (e.g. Google 2018, Facebook 2019). This should be compared with the average self-reported PUE of 1.58 among data centres participating in a recent survey (Uptime Institute 2018). The ultra-efficient systems of Facebook and Google have been carefully designed with energy efficiency in mind, and are often located in regions with cool climates to make use of free cooling.

\section{Efficient computing management}

Underutilized IT equipment and idling losses constitute a substantial power drain in data centres. Although servers and storage media have become increasingly energy-efficient when active, they 
typically spend very little time working at full capacity. The utilization profile and average level of utilization of servers differ from one data centre to another, and it is thus difficult to obtain reliable data in this regard. However, it has been suggested that the industry-wide average server utilization level is in the range of 10 to $30 \%$ (European Commission 2015). At least $20 \%$ of all servers are thus in constant idle mode, or "comatose", i.e. turned on, but not performing any computations. However, most data centre operators believe that less than $5 \%$ of their servers are comatose, and many do not even perform audits (Heslin 2014). An important way of improving efficiency in the data centre industry is to consolidate workloads, i.e. increasing the workload density and utilization level of a smaller number of active servers, rather than running a large number of underutilized servers. Virtualization technology is an enabler in this context. Data centre servers in 2010 handled on average 1.39 workloads simultaneously per physical server. In 2012, the value had increased 2.02, i.e. $45 \%$ higher (European Commission 2015). Rong et al. (2016) estimate that operators can save $10-15 \%$ of the electricity used in data centres by adopting better computing management strategies. However, many data centre operators today would be unable to fully implement such management strategies due to the ownership structures and legal practices in the cloud computing industry. A data centre operator does not always own the servers or have the legal mandate to consolidate workloads on them.

Considerable gains in energy efficiency through workload consolidation are possible through the ongoing centralization into cloud data centres. Large-scale cloud data centres also tend to have more adequate and efficient ancillary systems, which leads to further savings. In a study carried out in 2013, Masanet et al. (2013) found that if all US businesses switched to cloud solutions for their basic digital tools (such as email), the primary energy required to run these applications could be reduced by $87 \%$.

Potential for energy system integration

\section{Heat integration}

Practically all electricity consumed in a data centre is eventually transformed into heat that must be removed in order to keep the data centre running. Even with energy-efficient cooling, large amounts of waste heat are released that could have been utilized. Wahlroos et al. (2017) suggest focusing on energy reuse efficiency (ERE) $)^{4}$ instead of PUE as an efficiency metric to capture the use of waste heat. The waste heat from data centres is of low grade, and the temperature depends on the technology used for cooling. For example, air cooling typically results in outlet temperatures of 25 to $35^{\circ} \mathrm{C}$, while outlet temperatures of up to $60{ }^{\circ} \mathrm{C}$ are possible with liquid cooling, and novel two-phase systems can provide outlet temperatures up to $90{ }^{\circ} \mathrm{C}$ (Ebrahimi et al. 2014).

There are numerous ways in which waste heat can be utilized, such as the most common being direct use of waste heat for nearby offices or apartment blocks. It has also been suggested that small-scale distributed servers could be used as heat sources in individual apartments (Woodruff et al. 2013), where temperatures of 25 to $35{ }^{\circ} \mathrm{C}$ would be sufficient to meet heating demands. On a larger scale, utilizing waste heat in district heating systems is becoming common in Northern Europe (Wahlroos et al. 2018; Davies et al. 2016). For use in district heating, low-grade heat must be upgraded with heat pumps in order to reach temperatures of 75 to $120{ }^{\circ} \mathrm{C}$ for distribution in district heating networks, although fourth-generation district heating can be run with supply temperatures of 45 to $55^{\circ} \mathrm{C}$ (Wahlroos et al. 2018; Lund et al. 2014).

Several data centres are currently developing this concept in Scandinavia (Wahlroos et al. 2018). Stockholm Data Parks (2019) is an example where several data centres are co-located around a central heat pump station that increases the temperature of the waste heat and supplies the district heating network. This combined siting reduces the risk of the district heating company being reliant on a single data centre operator.

A third way of utilizing waste heat is for drying or heating in industrial processes. This is a development of the industrial symbiosis concept, where geographical proximity enables waste heat recovery/use between different plants. Drying of biomass is one option, as well as preheating in thermal power plants, thus increasing the efficiency (Ebrahimi et al. 2014). Waste heat can also be used for low-temperature applications such as greenhouses and aquaculture.

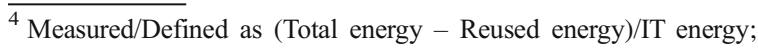
PUE $=$ Total energy/IT energy
} 


\section{Demand response}

Integrating renewables in their electricity mix has become interesting for some data centre operators in recent years as a means of reducing their carbon footprint and for branding. Numerous workload management strategies that align data centre activity with the availability of renewables have been suggested to this end. Although the objective so far has often been to increase the utilization of on-site renewables or to take advantage of low grid prices, the same strategies could be used to engage the data centre in power flexibility markets. Various strategies can be used to achieve a load shift. Scheduling delay-tolerant workloads within a data centre can lead to a temporal load shift (Goiri et al. 2014; Liu et al. 2012). For operators with geographically distributed data centres, workloads can be shifted between data centres in the network, leading to a spatial load shift (Chen et al. 2012; Liu et al. 2015; Toosi et al. 2017). By implementing constraints in the algorithms, workloads, and thus power demand, can be shifted without any negative impact on the quality of service.

In an electricity system dominated by solar and wind power, a major challenge will be to develop a reliable power system where flexible load management will be a key feature (Haas et al. 2013). Data centre load management strategies have considerable potential in this respect. As data centres are large electricity consumers, their participation in demand response is meaningful for system stability. They are also highly connected and automated, with components that are already monitored and responsive to control signals. These characteristics make them suitable candidates for demand response, with minimal infrastructure investments (Krioukov et al. 2011).

A US field study by Ghatikar et al. (2012) demonstrated that data centres can participate in demand response events with a duration of up to several hours and with a response time of 2-22 min. The study focuses on current possibilities and on automated response markets, and includes both geographic and temporal flexibility. The amount of workloads that could be shifted was estimated to correspond to $35 \%$ of the average power demand in this case study. Clausen et al. (2014) applied these/their results to the current situation in Denmark, where data centres consuming about $500 \mathrm{GWh} /$ year and $60 \mathrm{MW}$ were estimated to be able to provide $22 \mathrm{MW}$ of demand response. In a bottom-up calculation, Koronen (2018) estimated the maximum theoretical potential for demand response for data centres to be in the range of 38 to $80 \%$ of the installed power demand in 2030 . The size of the potential demand response as a share of the data centre's average or peak power will, however, vary from case to case, depending on the data centre. Furthermore, the duration of the applicable demand response events is typically in the range of minutes to hours, but depends on the type of workload handled by the data centre. The possibility of shifting the load geographically depends on the delay sensitivity of the data management.

\section{Innovative use of backup power}

Data centres are normally equipped with UPS units to ensure continuous and high-power quality, and for handling grid power failures. The UPS unit is part of the emergency power or backup power system which typically includes diesel generators. Typical UPS battery units have the capacity to power the data centre at its maximum power requirement for 5-30 min (Guo and Fang 2013), which allows the diesel generators to be started. Interest is growing in the more active use of UPS units for peak shaving and frequency regulation in power systems with increasing shares of variable renewable power generation (see, e.g. Shi et al. 2018).

Backup diesel generators are intended to be used only in the case of a power outage. From a power system perspective, this represents a large and underutilized potential for grid balancing in the future. With increasing needs for grid balancing and energy storage, as well as power technology development, considerable economic benefits may be obtained by designing microgrid systems for grid services and balancing, rather than for emergency backup power only (Luo et al. 2015; Ma et al. 2018). New clean technologies also allow for operation in areas where diesel generator emissions would have posed a problem. Fuel cell systems appear to be particularly promising in this regard, but the potential and various technological options for data centres seem to be relatively unexplored (Ma et al. 2018; Navigant 2017).

It is quite conceivable that future data centres will be highly integrated into power systems by routinely utilizing capacity that was formerly perceived as backup emergency power. Several data centre operators are aiming at $100 \%$ renewable electricity on an annual basis. It would be a logical follow-on from that to use $100 \%$ renewable electricity at every stage by using emerging electricity storage options such as power-to- 
gas storage and fuel cells, or flow batteries, in a microgrid $^{5}$ (Navigant 2017). The viability of such a system will depend partly on the regulations governing power production, and on markets, grid access and permits.

\section{Current EU policies concerning data centres and energy}

The European Union has several policies promoting energy efficiency and the development of ICT. The EU is engaged in facilitating digitalization, internet access and growth in the ICT industry. In 2015, the EU adopted a digital single market strategy (European Commission 2015b) for Europe, including the provision of better online access for customers and businesses, secure high-speed IT infrastructure, and building a digitalised economy. Digital transformation of both businesses and society is recognized by the EU as important for the economy.

The extent to which the data centre industry integrates with the energy system and adopts energy efficiency measures is important for the future development of the European energy system. This development will be influenced by EU policy: by regulations directly targeting data centres, and by other policy initiatives that define and create the market conditions for electricity, demand response and heating. In our mapping of policy initiatives, we have found only three EU initiatives that directly target energy use in data centres. These are discussed below.

\section{Energy efficiency through the Ecodesign Directive}

One of the primary EU policy initiatives for energy efficiency is the Ecodesign Directive (European Commission 2009). Servers and storage devices used in data centres will be included in the Ecodesign Directive through regulations entering into force in 2020. The inclusion of this product group is expected to result in energy savings of $37.5 \mathrm{TWh} /$ year in 2030 (European Commission 2016). Product group regulations under the

\footnotetext{
${ }^{5}$ A microgrid can be defined as (Navigant 2017): “... a distribution network that incorporates a variety of possible distributed energy resources (DER) that can be optimized and aggregated into a single system that can balance loads and generation with or without energy storage and is capable of islanding whether connected or not connected to a traditional utility power grid."
}

Ecodesign Directive set minimum mandatory efficiency requirements for products allowed on the European market. The regulations for data centre servers and storage devices will include thresholds for certain components and for idle power consumption, as well as material efficiency requirements. They will also force manufacturers to provide information on the energy performance of equipment.

Voluntary code of conduct

An energy efficiency initiative in place since 2008 is the EU voluntary Code of Conduct for Energy Efficiency in Data Centres (CoC). The aim of the CoC is to "inform and stimulate data centre operators and owners to reduce energy consumption [...] by improving understanding of energy demand within the data centre, raising awareness, and recommending energy-efficient best practices and targets" (European Commission 2016b). The total electricity consumption of the 289 reporting data centres in 2016 was 3.7 TWh (Avgerinou et al. 2017), corresponding to roughly $9 \%$ of European data centre electricity demand Parties join the $\mathrm{CoC}$ on a voluntary basis, either as participants, i.e. are data centre operators, or endorsers, who are other actors in the sector, such as vendors, consultants, customers, industrial associations or utility companies. Participants are required to monitor and report the energy efficiency of their data centre annually to the EC-JRC and to demonstrate continuous improvement over time. Endorsers commit to promoting the $\mathrm{CoC}$, and are obliged to report their activities. In addition to the reporting mechanism, a list of best practices forms a central component of the initiative. These best practices are a set of standards describing energy-efficient solutions in data centre design and operation $\dagger$. Some of these best practices are mandatory, while others are optional. The best practices are reviewed by industrial professionals as well as independent experts, and are updated periodically. They cover a wide range of design and operational factors relevant to energy efficiency in data centres $\dagger$ such as utilization, management and planning, IT equipment and services, cooling, power equipment, building design, and monitoring (Acton et al. 2018).

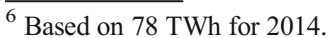


Research and development funded by horizon 2020

A third European policy instrument for energy efficiency in data centres is funding for research and development through the Horizon 2020 programme. The most recent call for funding applications has the title: "Bringing to market more energy efficient and integrated data centres", aimed at innovation that will lead to increased energy efficiency and energy system integration of data centres (European Commission 2019). The call places emphasis on innovative and energy-efficient cooling solutions, waste heat use, geographical and temporal workload balancing, integration of local and remote renewable energy sources, integration in smart grids, integration with district heating/cooling networks, integration of power backup systems in the grid, and the use of heat pumps for efficient use of waste heat. The projects funded by Horizon 2020 are, however, few and relatively small. Two projects have received funding of $€ 2-3$ million each (which represents $75-$ $85 \%$ of the projects' total budget). Furthermore, the focus of these projects is on energy efficiency and the reuse of low-grade heat, rather than on power grid integration. This suggests that the latter is not yet on the agenda for data centre operators. Alternatively, they may feel that exploring these issues within the framework of a public project is not interesting.

General digitalization and energy policies

Other more general policies also affect data centre energy efficiency opportunities. More flexible siting of data centres has been facilitated by the recently adopted EU General Data Protection Regulation, which is part of the EU digitalization policy (European Commission 2015c). Regulations governing how data are to be managed throughout the EU have created a legally level playing field in terms of storing and managing data within the EU (ibid). The digitalization policy is also a driver for increased use of centralized cloud services.

Apart from considerations regarding communication network latency and climate, the siting of data centres is influenced, to some extent, by the cost of electricity, especially in the case of mega-scale data centres. This is strongly affected by the level of energy taxation, other levies and grid access fees. Here, the definition between industries benefitting from the EU minimum energy tax and other privileges, such as exemption from renewable levies, and those that do not, differs between member states in the EU. Currently, Scandinavia, Ireland, the Netherlands and France define data centres as an "energy-intensive industry" thus qualifying for minimum taxes and levies. The difference in electricity cost between countries that give tax exemptions for data centres and countries that do not can be major. As an example, tax-exempted energy-intensive industries can have electricity costs around 40 euro/MWh, whereas industries with little or no tax exemptions could pay more than 150 euros/MWh. Some member states also apply different tax exemptions to mega-scale and medium-sized data centres.

A third and more general field of relevance is the whole governance of the electricity market regime which determines the market conditions for demand response. Several changes to the institutional framework are under development. The enabling and recent development of independent "aggregators", supported by the EU energy efficiency directive, is deemed key in providing flexibility to both customers and grid operators (Zancanella et al. 2018). The electricity market directive is also important in pushing for increased cross-border trade in electricity and balancing services between member states. The institutional framework for these changes was agreed upon in May 2019 at the EU level, and it is part of the Clean Energy for All Europeans package (European Commission 2019b). However, the degree of implementation of the previous directives for demand response differs considerably between member states, and although "demand response" is legal throughout the $\mathrm{EU}$, the regulations and institutional prerequisites, for example, for aggregators, grid operators and other key stakeholders, are far from clear in many member states (Bertoldi et al. 2016). The way in which the Energy Union and the associated directives regarding the electricity market regime are substantialized in the member states will determine how and to what extent demand response is actually realized.

\section{Potential and policy challenges}

The increased use of ICT is a key part of societal development, and data centres are thus becoming an increasingly important part of infrastructure. The data centre industry may be a driver for the transition to renewable energy sources if powered by green 
electricity, at high energy efficiency, and as flexible loads. ${ }^{7}$ In the following sections, we provide rough assessments of the potential for improved efficiency and integration, and discuss the challenges associated with policy.

Efficiency improvement and integration potential in 2030

Data centre energy efficiency is already improving rapidly, and it is important to maintain this improvement if data centre traffic and workloads develop as projected. Centralization and the replacement of small installations with cloud services are important drivers of overall energy efficiency and also facilitate energy system integration. With the EU climate and energy policy defined up to 2030 with legally binding targets, it is worthwhile to assess how much electricity data centres will use in order to estimate the potential for demand response and energy system integration.

The European Commission has predicted data centre electricity use in 2030 based on the generally accepted assumptions that the number of workloads and the volume of data traffic will continue to grow at a rate of $25 \%$ per year (see, e.g. Cisco 2018). Despite this massive growth, the Commission projects that the use of electricity will only increase from $58 \mathrm{TWh}$ in 2015 to 69.5 TWh in 2030. It is here assumed that improvements in energy efficiency will be substantial due to virtualization and increased chip performance, thus keeping the increase in electricity use at a modest rate, and that the average PUE will decrease steadily from 2.0 to 1.5 over the same period. However, the estimated total electricity use for data centres in 2015 of $58 \mathrm{TWh}$ in the Commission's base case analysis is probably a low value. As pointed out in the same study, a more realistic estimate for data centre use in 2015 is $78 \mathrm{TWh}$ (European Commission 2015). Adapting the EU 2030 scenario to this results in a data centre electricity use of about 90 TWh in 2030, which is the value used in Fig. 1.

To illustrate the importance of continued improvements in energy efficiency in data centres and ICT, Fig. 1 shows the increase in electricity use over time if some of these key efficiency gains are not realized. The

\footnotetext{
${ }^{7}$ Greenpeace (2017) expresses it thus: "If data centers and other digital infrastructure are $100 \%$ renewably powered, our increasing reliance on the internet can actually accelerate our transition to a renewably powered economy."
}

most important factor for efficiency in the EU scenario is the assumed autonomous improvement in electricity use per workload that will continue to follow Moore's law up to 2030. A counterfactual scenario in which the electricity use per workload remains the same ("Frozen efficiency") is also shown in Fig. 1. However, this is not a realistic scenario as the assumed continued growth in data handling is dependent on increasing chip performance. A substantially less optimistic scenario regarding energy efficiency gains has been proposed by Andrae and Edler (2015), and is recalculated at an EU level $^{8}$ is also shown in Fig. 1. Their scenario would result in an electricity use of almost $600 \mathrm{TWh}$ per year, which also seems unrealistic from the energy supply and cost perspectives, but demonstrates the risk of relying on autonomous efficiency gains if the development according to Moore's law slows down. The EU "Frozen PUE efficiency" scenario is also included in Fig. 1 to illustrate the effect of maintaining the PUE at 2.0.

If we assume the EU scenario in which the electricity use by data centres in 2030 is to be $90 \mathrm{TWh}$, we can then estimate the potential for demand response. According to the assumptions made by Koronen (2018), $90 \mathrm{TWh}$ corresponds to an average load of about $10 \mathrm{GW}$ with an average server utilization rate in 2030 of $30 \%$ and an installed maximum load of about $23 \mathrm{GW}$. The theoretical potential for demand response was estimated based on the assumptions given by Koronen (2018) and the practical potential based on the assumptions of Ghatikar et al. (2012) both of which are given in Table 1. The estimate based on the study by Ghatikar et al. (2012) indicates what would be possible given current practices and market regimes based on specific cases in the USA, whereas our estimate based on the study by Koronen (2018) is a maximum theoretical value given. Higher electricity demand would correspond to higher loads and higher potential for demand response. The values given in Table 1 do not include the potential use of emergency backup power equipment for power system balancing.

For comparison, the theoretical potential was estimated to be $28 \%$ of the EU peak load, or about $160 \mathrm{GW}$, in an impact assessment study of the total potential demand response for all end-use sectors in the EU (COWI/European Commission 2016). Data centres were not listed among the electricity end uses whose

\footnotetext{
${ }^{8}$ Assuming that EU data centres represent $20 \%$ of the global fleet, which is the current share (European Commission 2015).
} 
EU Data centre use 2015 to 2030 under different assumptions of PUE

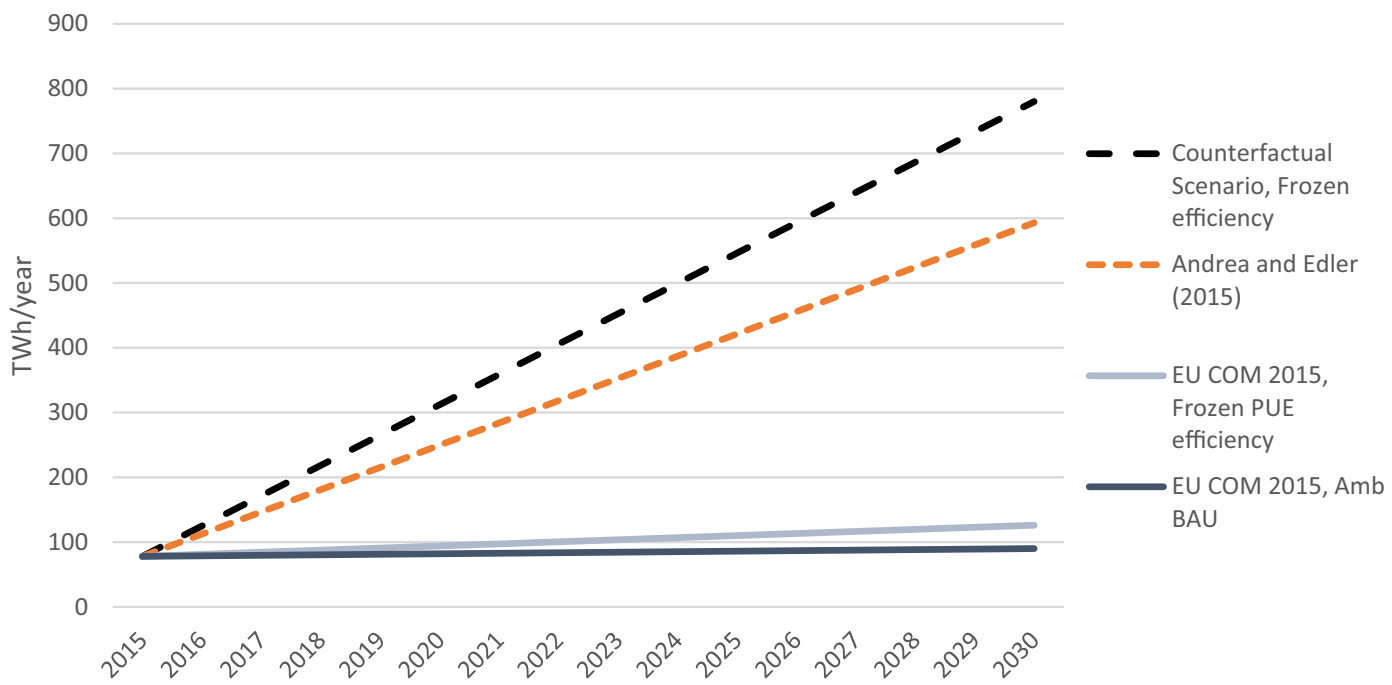

Fig. 1 (i) Workloads assumed to increase ten-fold by 2030 (European Commission 2015), consistent with Cisco (2018), and Andrae and Edler (2015). (ii) Counterfactual scenario assuming that energy/workload remains unchanged. (iii) Andrae and Edler assumed that efficiency gains according to Moore's Law would

potential for demand response was considered in this study, probably because little or no information was available. In our assessment, data centres could add several GW to that potential. It should also be noted that $23 \mathrm{GW}$ of installed capacity with an average use of $10 \mathrm{GW}$ would result in a large amount of installed emergency backup power capacity. If this was used actively, e.g. in microgrid solutions, it could be used

Table 1 Potential for demand response for the EU Scenario of $90 \mathrm{TWh}$ data centre energy use in 2030

\begin{tabular}{ll}
\hline Demand response $(\mathrm{GW})^{\mathrm{a}}$ & 2030 \\
\hline Theoretical upper limit based on Koronen $(2018)^{\mathrm{b}}$ & 8 to $18 \mathrm{GW}$ \\
Current practical potential based on & 2.5 to $3.5 \mathrm{GW}$ \\
$\quad$ Ghatikar et al. $(2012)^{\mathrm{c}}$ &
\end{tabular}

${ }^{\mathrm{a}}$ Response rates are rapid ( 2 to 20 min according to Ghatikar et al. (2012)) and the demand response (DR) is available for a period varying from less than $1 \mathrm{~h}$ up to 1 day

${ }^{b}$ Koronen (2018) estimated the theoretical limits of DR on the EU level assuming a centralized and common DR response of all data centres, which is highly unlikely. The DR potential can be separated into "time shifting" (batch loads) and "geographic shifting" (interactive loads)

${ }^{\mathrm{c}}$ Ghatikar et al. (2012) is based on current market regimes and on automated response markets that do not interrupt data centre operations in any way. The calculation is based on the assumption that $25-35 \%$ of the average power use can be demand response slow down considerably after 2020. (iv) Both European Commission (2015) scenarios assume that efficiency gains according to Moore's Law continues until 2030. (v) "Frozen PUE efficiency" means PUE $=2.0$. Computation efficiency assumed to increase according to Moore's law

for energy storage, adding several GW of potential demand response in future power grids.

As all electricity eventually becomes waste heat, the theoretical potential for waste heat recovery from data centres in our scenario would be $>80 \mathrm{TWh}$. However, the estimated total amount of waste heat in the EU is already approximately $3000 \mathrm{TWh}$, which is roughly equal to the current heat demand of the EU. Waste heat utilization will thus be determined by user-side needs as availability is not usually a problem. User-side needs are determined by infrastructure availability (district heating, pipes), legislation and market regimes, which are largely determined at national level, and not by the EU (Wahlroos et al. 2017). Persson et al. (2014) estimated that $46 \%$ of current waste heat could be used, but only a minor proportion is actually utilized, as incentives for waste heat recovery are weak and not prioritized (Persson et al. 2014). Data centre location, together with the development of policy incentives, will thus be key in determining how much of the waste heat generated by data centres could be utilized.

\section{Policy challenges}

The European Commission faces several challenges in trying to guide future data centre development in a sustainable direction. The first challenge is that 
development of data centres and associated infrastructures in the digitalized economy is proceeding very rapidly, making predictions uncertain. This is driven by a highly innovative industry, and the adoption of regulative policies will thus be slow compared to technology and market development. A second challenge is the division of competences between member states and the EU, where the member states have a substantial influence over how various energy policies are implemented.

Among the three policies that directly affect data centres, identified in "Current EU policies concerning data centres and energy", the Ecodesign Directive is a regulative tool that can prevent the least energy-efficient servers from being sold on the European market. Regulating the energy efficiency of data centre servers and storage devices under the Ecodesign Directive is more difficult than regulating, for example, light sources and domestic appliances. The development of the technology is faster, and the operating modes of servers and storage devices are more complex (IEA 2017). It is therefore difficult to define fair and purposeful energy performance standards, and the resulting energy savings are difficult to measure and verify. Furthermore, the energy performance of individual data centre components constitutes only part of the overall efficiency. Regulating equipment is motivated, but it is not sufficient to ensure overall efficient operations.

The Code of Conduct/CoC for Energy Efficiency in Data Centres is a relatively weak voluntary agreement that encourages industry to network, find energyefficient solutions, and share best practices. Given the complexity and rapid development of the data centre industry, it seems appropriate to use a voluntary agreement such as the $\mathrm{CoC}$. Experience from earlier programmes focusing on energy efficiency in data centres highlights the need to understand the rapid pace of innovation and the specific decision-making process within the data centre industry in order to be effective (see, e.g. Howard and Holmes 2012). A voluntary approach allows industrial actors to develop and share best practices, while at the same time allowing public authorities to become involved and build up their knowledge and technical capacity. Voluntary approaches can thus serve the purpose of informing policy-makers of what is industrially feasible. The experience gained could be translated in the next step into regulative demands, for example, in the Ecodesign Directive. Challenges include ensuring broad participation and enhancing effectiveness by accelerating technology development and realizing potentials.

Promoting research and development through funding is a sensible policy/approach to develop and demonstrate new solutions that are early in terms of technology readiness level, but not yet ready for commercial application. Typical challenges for policymakers include balancing public and private funding. Publicly funded research and development will be especially important if the, so far mainly market-driven, efficiency gains from ever increasing chip performance (Moore's law) indeed level out (Waldrop 2016), but will also be crucial for developing and demonstrating how data centres could find profitable business models for increased participation in demand response markets.

We have highlighted the potential for greater energy system integration through the use of waste heat and through more demand response. Siting considerations are important, both for energy efficiency and for system integration. One challenge, from the EU perspective, is that the definition of what constitutes an "energy-intensive industry" and thereby qualifies for substantial tax exemption, varies between member states, and thus influences siting, especially in the case of mega-scale data centres where the price of electricity is key. A coordinated approach throughout the EU would ensure a level playing field and thus benefit the rational localization of data centres from an energy integration perspective.

\section{Concluding discussion}

Our work shows that there are considerable potentials for both improved efficiency and renewable energy system integration in the data centre industry. Increased efforts from both policy-makers and industry are needed in the coming 10 years to capture this potential and to benefit future energy system efficiency and flexibility. It will require high resource and energy efficiency in data centres and that enabling technical infrastructure as well as legal frameworks are put in place.

It is difficult to govern efficient electricity use in the data centre industry due to its complex infrastructure and operations, and its rapid development. However, this should not discourage from continued efforts through the Ecodesign Directive or other ways of implementing energy performance standards. Here, coordination across different policy domains is important 
in providing direction and levelling the playing field. One approach could be through the Industrial Emissions Directive (IED), which specifies the best available technologies as a basis for permit procedures. Negotiated or voluntary agreements can be further developed with stronger incentives to promote best practices and support forerunners in efficiency and integration measures (e.g. offering lower electricity taxes to participating companies in exchange for commitments). Electricity tax exemptions are now provided in some countries to attract investments in data centres but without demanding anything in return. This weakens the financial incentives for energy efficiency and creates perverse incentives for geographical siting. The taxation of electricity used in digital services must be discussed in a broader context, as harmonization across the EU is desirable.

With regard to energy system integration, there are potentials but they must be further assessed both in terms of technical options and the implications for regulation. According to our assessment, future data centres may offer several to tens of GW of potential demand response, but the details of this are so far not well understood. Little attention is devoted to it, even in research and development projects. This motivates more technology R\&D, policy development towards creating enabling market conditions, as well as enhanced cooperation between data centres and the energy industry. Electricity and heat market infrastructure, market design and regulations are critical for facilitating energy system integration and realizing the potential for demand response and heat recovery. Knowledge and institutional capacity building in this rapidly developing field are important for developing better and more effective governance and policy approaches.

The current policy initiatives, including the Ecodesign Directive with minimum performance standards, the Code of Conduct with best practices, and the Horizon 2020 projects for new technical solutions, do provide a good foundation. In particular, it is important to spread and disseminate good practices and best available technologies beyond the forerunners. However, these initiatives should be seen as a steppingstone towards future and intensified efforts. Furthermore, in our assessment, the governance in this sector is currently characterized more by carrots (e.g. various efforts to attract investments) than sticks (e.g. regulations, market design and taxes to promote system efficiency). The balance between sticks and carrots is a political issue, but it is important that opportunities for energy- and resource-efficient solutions are not lost in this formative and expansive phase of the data centre industry.

Acknowledgements Open access funding provided by Lund University.

\section{Compliance with ethical standards}

Conflict of interest The authors declare that they have no conflict of interest.

Open Access This article is licensed under a Creative Commons Attribution 4.0 International License, which permits use, sharing, adaptation, distribution and reproduction in any medium or format, as long as you give appropriate credit to the original author(s) and the source, provide a link to the Creative Commons licence, and indicate if changes were made. The images or other third party material in this article are included in the article's Creative Commons licence, unless indicated otherwise in a credit line to the material. If material is not included in the article's Creative Commons licence and your intended use is not permitted by statutory regulation or exceeds the permitted use, you will need to obtain permission directly from the copyright holder. To view a copy of this licence, visit http://creativecommons.org/licenses/by/4.0/.

\section{References}

Acton, M., Bertoldi, P., Booth, J., Newcombe, L., Rouyer, A., \& Tozer, R. (2018). 2018 Best Practice Guidelines for the EU Code of Conduct on Data Centre Energy Efficiency. EUR 29103 EN. Luxembourg: Publications Office of the European Union.

Andrae A. (2018). Should we be concerned about the power consumption of ICT? Presentation at the Around the World Sustainable Research e-Conference, Alberta, Canada, May 4.

Andrae, A., \& Edler, T. (2015). On global electricity usage of communication technology: trends to 2030. Challenges, 6 , $117-157$.

Artelys. (2017). Cleaner, smarter, cheaper - responding to opportunities in Europe's changing energy system. Available online: https://www.energyunionchoices.eu/cleanersmartercheaper/

Avgerinou, M., Bertoldi, P., \& Castellazzi, L. (2017). Trends in data centre energy consumption under the european code of conduct for data centre energy efficiency. Energies, 10(10), 1470. https://doi.org/10.3390/en10101470.

Banja, M., \& Jégard, M. (2017). Renewable technologies in the EU electricity sector: trends and projections. Luxembourg: Publications Office of the European Union (publication nr. JRC109254).

Bertoldi, P., Hirl, B., \& Labanca, N. (2012). Energy efficiency status report 2012. In Electricity consumption and efficiency trends in the EU -27. EUR - Scientific and Technical 
Research series. Luxembourg: Publications Office of the European Union.

Bertoldi P., Zancanella P., Boza-Kiss B. (2016) Demand response status in EU Member states, EUR 27998 EN; doi: https://doi. org/10.2790/962868.

Boden Type DC One. (2018). The datacenter - Boden Type DC One, https://bodentypedc.eu/one/the-datacenter

Capozzoli, A., \& Primiceri, G. (2015). Cooling systems in data centres: state of art and emerging technologies. Energy Procedia, 83, 484-493 $7^{\text {th }}$ International Conference on Sustainability in Energy and buildings.

Chen, C., He, B. and Tang, X. (2012) Green-aware workload scheduling in geographically distributed data centers, in 4th IEEE international conference on cloud computing technology and science proceedings. Taipei, Taiwan: IEEE, pp. 8289.

Cisco. (2016). Global cloud index - Forecast and Methodology 2015-2020.

Cisco (2018). Global cloud index - Forecast and Methodology 2016-2021.

Clausen A., Ghatikar G., Nørregaard Jørgensen B. (2014). Load management of data centres as regulation capacity in Denmark. In: Proceedings International Green Computing Conference, 3-5 Nov. 2014, Dallas USA, https://doi. org/10.1109/IGCC.2014.7039161.

COWI/European Commission. (2016). Impact assessment study on downstream flexibility, price flexibility, demand response \& smart metering. DG Energy (request nr. ENER/B3/2015641).

Davies, G. F., Maidment, G. G., \& Tozer, R. M. (2016). Using data centres for combined heating and cooling: an investigation for London. Applied Thermal Engineering, 94, 296-304.

Ebrahimi, K., Jones, G. F., \& Fleischer, A. (2014). A review of data centre cooling technology, operating conditions and the corresponding low-grade waste heat recovery opportunities. Renewable and Sustainable Energy Review, 31, 622-638.

European Commission. (2009). Directive 2009/125/EC of the European Parliament and of the Council of 21 October 2009 establishing a framework for the setting of ecodesign requirements for energy-related products.

European Commission. (2011). Energy Roadmap 2050, Brussels, 15.12.2011 COM(2011) 885 final communication from the commission to the European Parliament, the Council, the European economic and Social Committee and the Committee of the Regions.

European Commission. (2015). Ecodesign preparatory study on enterprise servers and data equipment. Luxembourg: Publications Office of the European Union.

European Commission (2015b) Communication from the Commission to the European Parliament, the Council, the European Economic and Social Committee and the Committee of the Regions: a digital single market strategy for Europe. COM(2015) 192 final.

European Commission (2015c) Brussels, 6.5.2015 COM(2015) 192 final communication from the Commission to the European Parliament, the Council, the European Economic and Social Committee and the Committee of the Regions a digital single market strategy for Europe.

European Commission (2016) Final report: Ecodesign technical assistance study on standards for lot 9 Enterprise servers and
Enterprise data storage. Luxembourg: Publications Office of the European Union.

European Commission. (2016b). Code of Conduct for Energy Efficiency in Data Centres https://ec.europa. eu/jrc/en/energy-efficiency/code-conduct/datacentres [201811-21].

European Commission. (2018). In-depth analysis in support of the Commission Communication COM (2018) 773 A Clean Planet for all A European long-term strategic vision for a prosperous, modern, competitive and climate neutral economy, Brussels.

European Commission. (2019). Bringing to market more energy efficient and integrated data centres. https://ec.europa. e u / i n f o / f u n d i n g tenders/opportunities/portal/screen/opportunities/topicdetails/ee-20-2017 [2019-11-05].

European Commission. (2019b). Clean energy for all Europeans package adopted, https://ec.europa. eu/energy/en/topics/energy-strategy-and-energyunion/clean-energy-all-europeans [2019-05-22].

Eurostat. (2019). Energy statistics from https://ec.europa. $\mathrm{eu} /$ eurostat/web/energy/data

F a c e b o o k ( $\left.\begin{array}{llll}2 & 0 & 1 & 9\end{array}\right)$ w w w. f a c e b o o k. com/LuleaDataCenter/app/115276998849912/ [2019-12-20].

Ghatikar R.,Ganti V., Matson N. and Piette M. (2012) Demand response opportunities and enabling technologies for data centers: findings from field studies Report number: LBNL5763E, Affiliation: Lawrence Berkeley National Laboratory.

Goiri, Í., Haque, M. E., Le, K., Beauchea, R., Nguyen, T. D., Guitart, J., Torres, J., \& Bianchini, R. (2014). Matching renewable energy supply and demand in green datacenters. Ad Hoc Networks, 25(February), 520-534.

Google. (2018). Efficiency: how we do it. Available at: h t t p s : / / w w w. g o o g 1 e . com/about/datacenters/efficiency/internal/ [2018-10-18].

Guo, Y., \& Fang, Y. (2013). Electricity cost saving strategy in data centers by using energy storage. IEEE Transactions on Parallel and Distributed Systems, 24(6).

Haas, R., Lettner, G., Auer, H., \& Duic, N. (2013). The looming revolution: how photovoltaics will change electricity markets in Europe fundamentally. Energy, 57, 38-43.

Heslin K. (2014). 2014 data center industry survey. Uptime Institute. Available at: https://journal.uptimeinstitute. com/2014-data-center-industry-survey/ [2018-11-20].

Howard A.J., and Holmes J., (2012) Addressing data center efficiency: lessons learned from process evaluation of utility energy efficiency programs. Energy Efficiency 5. 137-148. Doi https://doi.org/10.1007/s12053-011-9128-4.

IEA (2017), Digitalization and energy, IEA Publications, Cedex, Paris.

IEA (2019). Data center and data transmission networks. Available at: https://www.iea.org/tcep/buildings/datacentres/ [2019-08-20].

IRENA. (2019). Renewable power generation costs in 2018. Abu Dhabi: International Renewable Energy Agency.

Khalaj, A. B., \& Halgamuge, S. K. (2017). A review on efficient thermal management of air- and liquid-cooled data centers: from chip to the cooling system. Applied Energy, 205, 11651188.

Kondziella H. and Bruckner T. (2016) Flexibility requirements of renewable energy based electricity systems - a review of 
research results and methodologies Renewable and Sustainable Energy Reviews Volume 53, January 2016, Pages 10-22.

Koomey, J. (2008). Worldwide electricity used in data centers. Environmental Research Letters, 3(034008), September 23.

Koomey, J. (2011). Growth in data center electricity use 2005 to 2010. Oakland, CA: Analytics Press July.

Krioukov, A., Goebely, C., Alspaugh, S., Chen, Y., Culler, D. and Katz, R. (2011) Integrating renewable energy using data analytics systems: challenges and opportunities, IEEE Data Eng. Bull., 34(1), pp. 3-11.

Lechtenböhmer, S., Nilsson, L. J., Åhman, M., \& Schneider, C. (2016). Decarbonising the energy intensive basic materials industry through electrification - Implications for future EU electricity demand. Energy, 115, 1623-1631. https://doi. org/10.1016/j.energy.2016.07.110.

Liu, Z., Chen, Y., Bash, C., Wierman, A., Gmach, D., Wang, Z., Marwah, M., \& Hyser, C. (2012). Renewable and cooling aware workload management for sustainable data centers. In Proceedings of the 12th ACM SIGMETRICS/ PERFORMANCE joint international conference on Measurement and Modeling of Computer Systems.

Liu, Z., Lin, M., Wierman, A., Low, S., Andrew, L. L. H., \& Member, S. (2015). Greening geographical load balancing. IEEE/ACM Transactions on Networking, 23(2), 657-671.

Lund, H., Werner, S., Wiltshire, R., Svendsen, S., Thorsen, E., Hvelplund, F., \& Vad, M. B. (2014). 4th Generation District Heating (4GDH): integrating smart thermal grids into future sustainable energy systems. Energy, 68, 1-11.

Luo, X., Wang, J., Dooner, M., \& Clarke, J. (2015). Overview of current development in electrical energy storage technologies and the application potential in power system operation. Applied Energy, 137, 511-536.

Ma, Z., Eichman, J., \& Kurtz, J. (2018). Fuel cell backup power system for grid service and micro-grid in telecommunication applications: Preprint. Golden, CO: National Renewable Energy Laboratory. NREL/CP-5500-70990.

Masanet, E., Brown, R., Shehabi, A., Koomey, J., \& Nordman, B. (2011). Estimating the energy use and efficiency potential of U.S. Data Centers in Proceedings of the IEEE, 99(8), 14401453.

Masanet E., Shehabi A., Ramakrishnan L., Liang J., Ma X., Walker B., Hendrix V. and Mantha P. (2013). The energy efficiency potential of cloud-based software: a U.S. case study. LBNL-6298E, Lawrence Berkeley National Laboratory, Berkeley, California.

Murshed, S. M. M., \& de Castro, C. A. N. (2017). A critical review of traditional and emerging techniques and fluids for electronics cooling. Renewable and Sustainable Energy Reviews, $78,821-833$.

Navigant (2017) Data centers and advanced microgrids: meeting resiliency, efficiency, and sustainability goals through smart and cleaner power infrastructure, Navigant report by Peter Asmus, commissioned by Schneider Electric.

Ni, J., \& Bai, X. (2016). A review of air conditioning energy performance in data centers. Renewable and Sustainable Energy Reviews, 67, 625-640.

Oró, E., Depoorter, V., Garcia, A., \& Salom, J. (2015). Energy efficiency and renewable energy integration in data centres. Strategies and modelling review, Renewable and Sustainable Energy Reviews, 42, 429-445.
Papaefthymiou, G., \& Dragoon, K. (2016). Towards 100\% renewable energy system: uncapping power system flexibility. Energy Policy, 92, 69-82.

Persson, U., Möller, B., \& Werner, S. (2014). Heat roadmap Europe: identifying strategic heat synergy regions. Energy Policy, 74, 663-681.

Rahman A., Liu X. and Kong F. (2014). A survey on geographic load balancing based data center power management in the smart grid environment. Communications Surveys \& Tutorials, IEEE. 16. 214-233.

Rong, H., Zhang, H., Xiao, S., Li, C., \& Hu, C. (2016). Optimizing energy consumption for data centers. Renewable and Sustainable Energy Reviews, 58, 674-691.

Schleisser-Tappesser, R. (2012). How renewables will change electricity markets in the next five years. Energy Policy, 48(2012), 64-75.

Shehabi, A., et al. (2016). United States data center energy usage report. Berkeley, CA. Available at: https://eta.lbl. gov/publications/united-states-data-center-energy.

Shi, Y., Xu, B., Wang, D., \& Zhang, B. (2018). Using battery storage for peak shaving and frequency regulation: joint optimization for superlinear gains. IEEE Transactions on Power Systems, 33(3).

Shuja J., Gani A., Shamshirband S., Ahmad R.W. and Bilal K. (2016) Sustainable cloud data centers: a survey of enabling techniques and technologies, Renewable and Sustainable Energy Reviews, vol. 62, pages 195-214.

Stockholm Data Parks (2019). Our mission. Available at: https://stockholmdataparks.com/green-computing-redefined/ [2019-08-20].

The Economist. (2015). Ever more from Moore available, The Economist April 18. Available at: https:/www.economist. com/business/2015/04/18/ever-more-from-moore

Toosi, A. N., Qu, C., de Assunção, M. D., \& Buyya, R. (2017). Renewable-aware geographical load balancing of web applications for sustainable data centers. Journal of Network and Computer Applications., 83(January), 155-168.

Uptime Institute. (2018). Uptime institute global data center survey. Seattle, USA: Uptime Institute Available at: https://uptimeinstitute.com/2018-data-center-industrysurvey-results.

Van Heddeghem, W., Lambert, S., Lannoo, B., Colle, D., Pickavet, M., \& Demeester, P. (2014). Trends in worldwide ICT electricity consumption from 2007 to 2012. Computer Communication, 50, 64-76.

Wahlroos, M., Pärssinen, M., Manner, J., \& Syri, S. (2017). Utilizing data center heat in district heating - impacts on energy efficiency and prospects for low-temperature district heating networks. Energy, 140, 1228-1238.

Wahlroos M., Pärssinen M., Rinne S., Syri S:, Manner J (2018) Future views on waste heat utilization - case of data centers in Northern Europe. Renewable and Sustainable Energy Reviews 82, pp 1749-1764.

Waldrop M (2016) More than Moore, Nature, v 530, February 2016.

Wang N., Zhang J.F. and Xia X.H. (2013) Energy consumption of air conditioners at different temperature set points. Energy and Buildings 2013; 65: pp. 412-418.

Wong, H., Koomey, J., Berard, S., \& Sanchez, M. (2011). Implications of historical trends in the electrical efficiency 
of computing. IEEE Annals of the History of Computing, 33(03), 46-54.

Woodruff, J.Z., Brenner P., Buccellato A.P.C., Go D.B, (2013) Environmentally opportunistic computing: a distributed waste heat reutilization approach to energy-efficient buildings and data centers, Energy and Buildings (2013), https://doi.org/10.1016/j.enbuild.2013.09.036

Zancanella, P. M., Bertoldi, P., \& Boza-Kiss, B. (2018). Why is demand response not implemented in the EU? Status of demand response and recommendation to allow demand response to be fully integrated in energy markets. ECEEE
2017 SUMMER STUDY - CONSUMPTION, EFFICIENCY \& LIMITS.

Zhang, H., Shao, S., Xu, H., Zou, H., \& Tian, C. (2014). Free cooling of data centres: a review. Renewable and Sustainable Energy Reviews, 35, 171-182.

Publisher's note Springer Nature remains neutral with regard to jurisdictional claims in published maps and institutional affiliations. 